OPEN ACCESS

Edited by:

Mirta Schattner,

National Council for Scientific and

Technical Research

(CONICET), Argentina

Reviewed by:

Luiz Gustavo Gardinassi,

University of São Paulo, Brazil

Rosana Fernanda Marta,

National Council for Scientific

and Technical

Research (CONICET), Argentina

${ }^{*}$ Correspondence:

Catarina Teixeira

catarina.teixeira@butantan.gov.br

Ana Marisa Chudzinski-Tavassi

ana.chudzinski@butantan.gov.br

Specialty section:

This article was submitted to

Inflammation,

a section of the journal

Frontiers in Immunology

Received: 14 May 2019

Accepted: 16 August 2019

Published: 04 September 2019

Citation:

Teixeira C, Fernandes CM, Leiguez E and Chudzinski-Tavassi AM (2019)

Inflammation Induced by

Platelet-Activating Viperid Snake Venoms: Perspectives on

Thromboinflammation.

Front. Immunol. 10:2082.

doi: 10.3389/fimmu.2019.02082

\section{Inflammation Induced by Platelet-Activating Viperid Snake Venoms: Perspectives on Thromboinflammation}

\author{
Catarina Teixeira ${ }^{1,2 *}$, Cristina Maria Fernandes ${ }^{1,2}$, Elbio Leiguez ${ }^{1,2}$ and \\ Ana Marisa Chudzinski-Tavassi ${ }^{2,3 *}$ \\ ${ }^{1}$ Laboratory of Pharmacology, Butantan Institute, São Paulo, Brazil, ${ }^{2}$ Centre of Excellence in New Target Discovery, Butantan \\ Institute, São Paulo, Brazil, ${ }^{3}$ Laboratory of Molecular Biology, Butantan Institute, São Paulo, Brazil
}

Envenomation by viperid snakes is characterized by systemic thrombotic syndrome and prominent local inflammation. To date, the mechanisms underlying inflammation and blood coagulation induced by Viperidae venoms have been viewed as distinct processes. However, studies on the mechanisms involved in these processes have revealed several factors and signaling molecules that simultaneously act in both the innate immune and hemostatic systems, suggesting an overlap between both systems during viper envenomation. Moreover, distinct classes of venom toxins involved in these effects have also been identified. However, the interplay between inflammation and hemostatic alterations, referred as to thromboinflammation, has never been addressed in the investigation of viper envenomation. Considering that platelets are important targets of viper snake venoms and are critical for the process of thromboinflammation, in this review, we summarize the inflammatory effects and mechanisms induced by viper snake venoms, particularly from the Bothrops genus, which strongly activate platelet functions and highlight selected venom components (metalloproteases and C-type lectins) that both stimulate platelet functions and exhibit pro-inflammatory activities, thus providing insights into the possible role(s) of thromboinflammation in viper envenomation.

Keywords: snake envenoming, venom-induced inflammation, toxins, platelet activation, thromboinflammation

\section{INTRODUCTION}

\section{Thromboinflammation and Platelets}

Coordinated activation of inflammation and hemostatic responses following tissue injury or invading pathogens is a defense mechanism with an essential role in homeostasis maintenance, leading to a thromboinflammatory response, elimination of pathogens, tissue remodeling, and repair (1). In general, thromboinflammation results from activation of the cascade systems of the blood (the complement, contact, coagulation, and fibrinolytic systems) and activation of a complex multicellular blood system comprising platelets, endothelial cells, and various subsets of inflammatory leukocytes. The functional interdependence among these systems has been largely described, and plentiful cross-talk occurring between different system cascades has been demonstrated (2-5). However, if not properly controlled, activation of these cascade systems will trigger severe thromboinflammatory responses, which can extend systemically and damage remote 
organs. In diverse pathological conditions, a pro-inflammatory state combined with thrombotic events can produce multiorgan failure as a consequence of excessive platelet activation, coagulation, and fibrin deposition in the microvasculature $(5,6)$.

Platelets are the predominant cellular elements in the process of thromboinflammation. These anucleate cells are critical in maintaining hemostasis and in arresting blood loss. Platelets contain three types of secretory granules that are essential to maintain steady state hemostasis: $\alpha$-granules, the most abundant organelle in platelets, contain proteins endocytosed from plasma, or synthetized by megakaryocytes, such as PF4; dense granules contain nucleotides, serotonin, polyphosphate, calcium and magnesium; lysosomes contain acid hydrolases, such as $\beta$-hesosaminidase; and $\mathrm{T}$ granules. At the site of a vascular injury, platelets develop a series of highly regulated functions, which include adhesion to endothelial and subendothelial structures, followed by activation and aggregation, constituting the called first wave of hemostasis (7-9). Once platelets become aggregated, the coagulation cascade is initiated by the intrinsic or extrinsic cascades, leading to activation of prothrombin and culminating in thrombin generation. Thrombin, in turn, activates platelets by cleaving protease activated receptors (PARs) expressed on platelets' surface, leading to thrombus formation $(10,11)$. Thrombin is considered a central mediator of thromboinflammation and plays a central role in propagating microvascular thrombosis and inflammation (12). This mediator affects the vasculature components by cleaving components of coagulation, complement, and fibrinolytic systems, as well as by activating endothelial cells, leukocytes, vascular smooth cells, fibroblasts, and platelets (13-15).

A number of receptors are found on the membrane surface of platelets, such as GPIb-V-IX, GPVI, 5HT2A, TP, $\alpha 2 \mathrm{~A}, \mathrm{P} 2 \mathrm{Y} 1$, $\mathrm{P} 2 \mathrm{Y} 12$, integrin receptors, PARs, and toll-like receptors (TLRs) (16-21). Engagement of these receptors by their agonists triggers functional activities of platelets, being essential for the roles played by these cells in both physiological and pathological processes $(22,23)$.

Beyond hemostasis and thrombosis, platelets are involved in diverse physiological and pathological processes, including the innate immune response. Yet platelets, like many host defense cells, can detect pathogen associated molecular patterns (PAMPs) via TLRs expressed on their membrane $(24,25)$, promoting thrombus formation. In response to PAMPs presented via TLR4/MYD88, platelets release microbicidal products (26) and induce neutrophil degranulation and release of neutrophil extracellular traps (NETs) (27). In addition to anti-bacterial functions, NETs display pro-coagulant and prothrombotic activities and bind to von Willebrand Factor (vWF), inducing platelet recruitment. Further, neutrophil-derived serine proteases and extracellular nucleosomes induce thrombosis and fibrin formation (28), strengthening coagulation through local proteolysis of tissue factor pathway inhibitor (TFPI). Moreover, platelet-derived PDI promotes the decryption/activation of tissue factor by monocytes, contributing to fibrin generation (29). Therefore, platelets are immune effector cells since they are able to both recognize pathogens via TLRs and communicate with innate immune cells to enhance their prothrombotic functions. Moreover, they act as contact elements between the complement, coagulation, and contact activation systems (30). In this context, a variety of innate and adaptive immune responses and hemostatic disturbances are induced by animal venoms.

\section{Snake Venom}

Snake venoms consist of a complex mixture of bioactive molecules, known as toxins, which are delivered in their victims through bites and used for defense or predation. Toxins in turn exhibit a great diversity of chemical composition, including proteins, peptides, biogenic amines, lipids and polysaccharides, and exhibit strong activity and high specificity for their targets, which comprise virtually all physiological systems and tissues.

Venomous snakes belong to four main families, Viperidae, Elapidae, Atractaspididae, and Colubridae, and their venoms contain substances with diverse biochemical and biological activities. The Viperidae family comprises a medically important group of venomous snakes and accounts for the majority of death and morbidity worldwide compared to the others $(31,32)$. Snakes of this cosmopolitan family are currently arranged in three subfamilies: Viperinae, Azemiopinae, and Crotalinae (33). The Crotalinae, or "pit vipers," subfamily is the most diverse and widely distributed lineage of vipers and comprises species occurring both in the Old and New World (34). In general, viper snakebite envenomation causes systemic and prominent local effects in the victims. Systemically, these venoms induce hemostatic disturbances related to consumption coagulopathy via the action of their pro-coagulant toxins and bleeding, which may evolve into cardiovascular and respiratory failure and death $(35,36)$. Local effects include inflammation, with edema, pain and conspicuous leukocyte infiltration, hemorrhage, and myonecrosis.

Regarding systemic effects, there are clinical reports describing systemic and venous thrombosis and multiple cerebral, myocardial, and mesenteric infarctions in victims envenomed by Bothrops sp. snakes. In the case of envenomation induced by $B$. lanceolatus, histopathologic examination of cerebral, myocardial, and mesenteric small arteries and arterioles showed multifocal thrombotic microangiopathy and platelet aggregates, being endothelial cells found within microthrombi $(37,38)$.

Coagulopathy induced by viperid snake venoms is a consequence of activation of the clotting pathway by procoagulant toxins present in these venoms, resulting in clotting factor consumption. The enzymatic toxins interfering with coagulation are pro-coagulant proteases (prothrombin activators, thrombin-like enzymes, factor $\mathrm{X}$, and factor $\mathrm{V}$ activators) and anticoagulant proteases (factor IX and X inhibitors, protein $\mathrm{C}$ activator, anticoagulant $\mathrm{PLA}_{2} \mathrm{~s}$ ). The venom components acting on fibrinolysis are fibrinolytic enzymes and plasminogen activators (39-42). Finally, viperid venoms are known to act on platelets, and several venom components show high structural and functional similarities to different natural ligands of the platelet adhesion receptor, thus affecting platelet functions by different mechanisms, including (i) binding or degradation of vWF or platelet receptors, e.g., $\alpha 2 \beta 3$ integrin, (ii) 
activation of protease-activated receptors (PARs) by thrombinlike enzymes, (iii) modulation of adenosine diphosphate (ADP) release, and (iv) modulation of thromboxane $\mathrm{A}_{2} \quad\left(\mathrm{TXA}_{2}\right)$ formation. Both inhibition and activation of platelets by venom components contribute to venom-induced coagulopathy by depleting platelets, culminating in marked thrombocytopenia (39, 43-45).

Regarding activation of platelets, although the effects of isolated venom toxins have been investigated in detail, the potent activity of whole venoms of several species of Viperidae snakes to stimulate platelet function has not been well-established. $B$. jararaca snake venom has been demonstrated to activate platelet PARs, leading to platelet aggregation through the action of thrombin-like enzymes and prothrombin activators $(46,47)$. In addition, pro-secreting activity of $B$. jararaca on mouse and human washed platelets has been recently described. Release of PF4 and $\beta$-hexosaminidase from platelet $\alpha$-granules and lysosomes, respectively has been demonstrated (45). Increased expression of TF at the site of $B$. jararaca venom injection and in lungs of rats, as well as decryption of this factor, were found in an experimental model of envenomation. In this condition, levels of TF were increased in plasma, indicating that disseminated intravascular coagulation syndrome may occur during Bothrops envenomation (48). Similarly, B. atrox, and B. asper snake venoms are also able to activate platelet PARs by virtue of their thrombin-like enzymes $(49,50)$. In the case of $B$. asper, the presence of pro-thrombin activators is also evidenced (51). In addition, Crotalus durissus snake venoms and those from diverse species of Trimeresurus genus have also been demonstrated to activate platelets via the action of their thrombin-like enzyme content (49, 52-54).

\section{INFLAMMATION INDUCED BY VIPER SNAKE VENOM}

Inflammation is largely recognized to be closely associated with the onset of local and systemic toxicity induced by Crotalinae venoms. Although still incomplete, studies on the inflammatory activities of snake venoms in the Crotalinae subfamily, mainly those of the Bothrops genus, are robust in comparison with others of the same family and subfamily. Therefore, in this review, emphasis will be placed on the present knowledge of inflammatory reactions induced by Bothrops sp. snake venoms.

Bothrops sp. snake venom induces a set of gross inflammatory events, including edema, leukocyte migration, and a complex network of released mediators. These events can progress to either resolution or an excessive and uncontrolled inflammatory response, depending on the volume of venom injected into the victim.

Severe local edema is a relevant clinical finding in Bothrops snake-bitten victims $(55,56)$ that frequently leads to ischemia and neural compression, contributing to tissue loss and disability (57-59). Experimental studies on the dynamics of local inflammation caused by $B$. asper venom have demonstrated early plasma extravasation from small venules and adjoining capillary segments a few minutes after exposure to venom, followed by stasis in the microcirculation (60). The edematogenic response to Bothrops venoms was shown to be dependent on local release of well-known synergistic inflammatory mediators, which cause increased vascular permeability and/or vasodilation. Accordingly, the roles of histamine via $\mathrm{H} 1$ and $\mathrm{H} 3 / 4$ receptors, serotonin, bradykinin (61-63), platelet activating factor (PAF) (64), prostaglandins (PGs) derived from both cyclooxygenase 1 and 2 pathways (64-66), neurokinins (67), nitric oxide (NO) (68), and $\alpha-1$ and $\alpha-2$ adrenergic mediators $(61,69)$ have been demonstrated in several experimental studies. Participation of anaphylatoxins, including the complement components $\mathrm{C} 3$ and C5, in edema formation has also been shown (70-74). The diversity of mediators participating in edema formation induced by Bothrops sp. venoms can be partially explained by the ability of these venoms to induce degranulation of mast cells (62, 63). Furthermore, the ability of Bothrops asper snake venom to contract collecting lymphatic vessels of mouse mesentery followed by halting the flow of lymph was demonstrated, suggesting that disturbance of the lymphatic system by venom may contribute to development of edema in envenomed tissues (75).

A conspicuous infiltration of leukocytes into the local snakebite is another important characteristic of inflammation triggered by the majority of Viperidae viperid snake venoms $(55,56)$. Leukocytes are essential cells in host defense, and they respond to injury by releasing inflammatory mediators, performing phagocytosis and inducing production of potent microbicidal products. Several experimental studies have demonstrated that Bothrops sp. venoms induce time-dependent infiltration of leukocytes into the site of the bite, characterized by an early neutrophil influx followed by a late mononuclear cell infiltrate, that accumulates at the site of venom injection and in adjacent tissues (66, 76-79). Moreover, studies on the mechanisms of Bothrops snake venom-induced leukocyte recruitment have supported species-dependent differences in the ability of these venoms to activate the intrinsic chemotactic activities of neutrophils. Whereas, B. jararaca neither triggers oriented cell locomotion nor modifies the intrinsic ability of neutrophils to migrate in response to a chemoattractant factor (80), B. jararacussu induces neutrophil chemotaxis in vitro by a direct mechanism (81). Such variability is explained by the presence of a lectin in $B$. jararacussu venom that recognizes glycoligands on neutrophil surfaces, leading to chemotaxis of neutrophils $(82,83)$. Moreover, the ability of Bothrops sp. snake venom to stimulate expression of the adhesion molecules L-selectin, LFA-1, ICAM- 1, PECAM-1, and CD18 was described in an in vivo experimental model in mice (84). This effect was related to the action of inflammatory cytokines and leukotrienes released by the venom acting on endothelial cells and/or leukocytes (84-86).

Cytokines and chemokines are important mediators of cellcell communication and major mediators of the upregulation of adhesion molecule expression and chemotaxis of leukocytes (87). The involvement of cytokines and chemokines in Bothrops snake venom-induced recruitment of leukocytes has been suggested by many to be due to increased levels of Th1 class cytokines, the regulatory cytokine IL-10 and chemokines found at the 
site of injection of distinct species of Bothrops snake venoms $(64,66,77,86,88-92)$. Moreover, increased serum levels of IL$1 \beta$, IL- 6 , TNF- $\alpha$, IL-10, and IFN- $\gamma$ were found after injection of whole venoms from B. jararaca and B. asper into mice (93). Accordingly, increased levels of IL-6, IL- 8, TNF- $\alpha$, MIP- $1 \alpha$, and RANTES were detected in the serum of patients bitten by $B$. jararaca and B. asper snakes (94). In addition, the direct action of venoms on leukocytes, primarily neutrophils, and macrophages, lead to production and release of mediators. Release of COX1and COX2- derived prostaglandins, including $\mathrm{PGE}_{2}, \mathrm{PGD}_{2}$, and $\mathrm{TXA}_{2}$ and the 5-LO-derived $\mathrm{LTB}_{4}$, by neutrophils and macrophages has also been described $(85,86,94-96)$. Further, formation of NETs upon stimulation by distinct Bothrops sp. venoms was also recently demonstrated (97).

A recent study demonstrated that $B$. jararaca and $B$. jararacussu venoms induce nuclear translocation of the transcription factor NF-KB in human monocytes and mouse alveolar macrophages, and this transcription factor participates in production of IL-1 $\beta$. In addition, venom-induced activation of NF- $\mathrm{KB}$ was shown to be upregulated by $\mathrm{PGE}_{2}$ but downregulated by $\mathrm{LTB}_{4}(90)$. Although cytokines and eicosanoids are relevant for driving inflammatory events, the regulatory mechanisms underlying production of each group of mediators by Bothrops venoms and the cross-talk occurring between mediators has yet to be further investigated. Moreover, despite the importance of inflammasome assembly in the development of inflammatory processes (98), the potential role of this multiprotein complex in the inflammatory responses to snake venoms is still poorly understood. The beneficial role of the inflammasome in the host response to Crotalus atrox was demonstrated early (99), arguing for contribution of the inflammasome platform to the inflammatory effects of viper snake venoms.

In addition to the involvement of diverse inflammatory mediators, leukocyte infiltration induced by Bothrops snake venoms has been associated with generation of chemotactic fractions from the complement system. Participation of the C5a fraction of the complement system in B. asper venom-induced leukocyte migration was demonstrated in C5-deficient animals (100). The ability of several species of Bothrops snake venoms to activate the complement system, generating chemotactic fractions, has been demonstrated $(70,72,74)$. In this regard, activation of the complement cascade by 19 different Bothrops species from South and Central America was demonstrated to occur by one or more pathways through their action either by directly cleaving $\mathrm{C} 3$ and $\mathrm{C} 5$ factors or by inactivating the soluble C1 inhibitor, C1-INH factor $(71,72)$. Moreover, activation of the complement system by B. lanceolatus snake venom in human serum has been reported (101).

Another important feature of Bothrops sp. venoms is related to their ability to stimulate leukocyte functions, primarily production of microbicidal substances and phagocytosis. Studies have showed generation of reactive oxygen species (ROS) by macrophages and peritoneal leukocytes stimulated with Bothrops sp. snake venoms $(97,102)$. Further, increased production of hydrogen peroxide and nitric oxide by macrophages followed by generation of peroxynitrites induced by Bothrops snake venoms (103) and the ability of Vipera russelli, a snake of medical importance in Asia, to activate production of ROS in neutrophils were also described. Prolonged or excessive release of leukocyte-derived peroxynitrites and ROS enhances inflammatory processes and potentiates tissue damage at inflammatory sites (104-106). Studies attempting to block the damaging effects of either B. asper or Vipera russelli snake venoms using different antioxidant compounds and/or inhibitors of NO production did not show similar protective effects $(105,107)$. Interestingly, the beneficial role of neutrophils in host defense against the noxious effects of snake venoms was demonstrated by studies showing that experimentally induced neutrophil depletion in mice reduced skeletal muscle regeneration after myonecrosis induced by $B$. asper snake venom and a myotoxic phospholipase $A_{2}$ isolated from this venom. Absence of these phagocytic cells impaired the late recruitment of macrophages into the damaged tissue, abolishing the clearance of necrotic debris (108). In this sense, the role of neutrophils in regulating production of $\mathrm{NO}$ and some cytokines and chemokines was further demonstrated in mice injected with B. atrox (88).

A number of surface and cytosolic receptors expressed in innate immune cells are able to sense PAMPs, damage-associated molecular patterns (DAMPs), or venom-associated molecular patterns (VAMPs) with high sensitivity and specificity, namely, TLRs $(109,110)$. Once engaged, these recognition receptors trigger signaling pathways that culminate in the transcription of inflammatory genes related to inflammatory mediators, including cytokines and eicosanoids. Adaptor proteins, such as the myeloid differentiation factor 88 (MyD88), mediate major TLR-activated intracellular signaling pathways $(110,111)$. Although the importance of TLRs in triggering inflammation is well-recognized, studies on their participation in snake venominduced inflammation are scarce. Participation of TLR2 in inflammation via the MyD88 adaptor molecule induced by $B$. atrox snake venom was demonstrated in MyD88 knockout mice. These animals showed low infiltration of leukocytes into the site of venom injection and failed to produce Th1 and Th17 cytokines, CCL-2, $\mathrm{PGE}_{2}$, and $\mathrm{LTB}_{4}(112,113)$. Moreover, TLR2 was shown to be involved in the release of PGE2, IL-1 $\beta$, and IL-10 by macrophages stimulated with phospholipase $\mathrm{A}_{2}$ (MTIII) isolated from $B$. asper snake venom (114). Consistent with the importance of inflammation in tissue regeneration, the involvement of TLR4 in protection against muscular damage induced by $B$. jararacussu snake venom in mice has been reported (115). Moreover, besides inflammatory mediators, the exudate generated in Bothrops venom-damaged tissue was shown to contain a large array of DAMPs derived from the affected cells and extracellular matrix (92). Among the DAMPs identified in exudates of mice injected with $B$. asper venom, several are known to play roles in the inflammatory reaction, coagulation and complement systems and may be critical elements for the overlap between inflammation and thrombosis, thus favoring thromboinflammation. For instance, among identified DAMPs is fibrinogen, a component of the coagulation system with the ability to stimulate chemokine secretion by macrophages through TLR4 engagement (116), potentially favoring thromboinflammation. Furthermore, considering the presence of TLRs on platelets' surface and formation of 
DAMPS induced by viper venoms, it is plausible to suggest that thromboinflammation plays a role in the pathogenesis of viper envenomation. Hence, snake venom generates DAMPs by inducing inflammatory events and at the same time stimulating platelets and/or activating coagulation factors or endothelial cells, which may set up a pathway of thromboinflammation. This may thus culminate into formation of microthrombi, which may be critically associated to pathogenesis of snake envenomation.

\section{Inflammation Induced by Snake Venom Toxins}

To date, studies reporting venom components endowed with the ability to reproduce both the inflammatory and platelet activating effects induced by the whole venom are few. Among the best studied toxins are metalloproteinases and C-type lectin like proteins.

\section{Snake Venom Metalloproteases}

Coagulopathy following snake envenomation is triggered by pro-coagulant isolated toxins, in which metalloproteases play a relevant role by activating platelet function, the coagulation cascade, and fibrinolysis (48, 117-122).

The snake venom metalloproteases (SVMPs) comprise a subfamily of zinc-dependent enzymes of varying molecular mass and can be divided into three classes, depending on their domain organization: P-I, comprising only the metalloproteinase domain; P-II, having a metalloproteinase domain followed by a disintegrin-like domain; and P-III, comprising metalloproteinase, disintegrin-like, cysteine-rich domains and a lectin-like domain linked by disulfide bonds (123). Literature indicates that the precursor of SVMPs can be proteolytically cleaved at various interdomain sites, yielding molecules containing only the disintegrin or only the catalytic domain, followed by the disintegrin domain or even the complete SVMP containing all domains. Thus, the same venom may contain SVMPs with different molecular weights and variable domains $(123,124)$.

SVMPs have been reported to induce an intense inflammatory response, which has been associated with inflammation induced by the whole venom of Bothrops sp. snakes. In this context, Zychar et al. (125) demonstrated that the intensity of edema and hyperalgesia/allodynia, along with the interaction of leukocytes with endothelium, were significantly reduced in animals injected with $B$. jararaca snake venom pretreated with an inhibitor of SVMPs, confirming these enzymes as relevant contributors to the inflammatory reaction seen during Bothrops envenomation.

In vivo studies have demonstrated that SVMPs per se are able to induce increased levels of pro-inflammatory mediators and migration of leukocytes at the site of injection. After intraperitoneal injection, BaP1, a PI class SVMP from B. asper venom, induces increased levels of circulating neutrophils, followed by their infiltration into the site of injection. Participation of LECAM-1, CD18 and LFA- 1 adhesion molecules in this effect was demonstrated. Moreover, increased levels of IL$1 \beta$ and TNF- $\alpha$ in peritoneal washes collected from mice injected with BaP1 was shown (126). In addition, neuwiedase, another PI class SVMP from B. neuwiedi snake venom, was shown to induce inflammatory infiltration into gastrocnemius muscle and release of inflammatory mediators, such as KC, IL-1 $\beta$, and IL6, after intramuscular injection (127). Recently, the ability of the PI class BpirMP SVMP from B. pirajai snake venom to induce paw edema, recruitment of leukocytes and increased levels of nitric oxide, IL- 6 and TNF- $\alpha$ in the peritoneal exudate has been demonstrated. Furthermore, these events were shown to be mediated by mast cell degranulation, histamine, prostaglandins, and cytokine production (128). Regarding PIII class SVMPs, the capability of jararhagin, isolated from B. jararaca snake venom, to induce infiltration of leukocytes into the mouse air pouch, dependent on activation of macrophages and the proteolytic activity of this SVMP, has been demonstrated (129).

The ability of SVMPs to activate different cell types and trigger pro-inflammatory responses in vitro has also been evidenced. Moojenactivase (MooA), a PIII class SVMP from $B$. moojeni snake venom, has been shown to stimulate production of the inflammatory mediators TNF- $\alpha$, IL- 8 , and MCP- 1 by peripheral mononuclear cells (122). After stimulation with neuwiedase, murine peritoneal adherent macrophages release significant levels of pro-inflammatory mediators, such as KC, IL-1 $\beta$, and IL-6. Stimulation of satellite muscle cells (lineage C2C12) with neuwiedase caused release of the KC chemokine (127). In addition, HF3, a PIII class SVMP isolated from $B$. jararaca venom, induced phagocytosis of opsonized zymosan particles by eliciting macrophages in a process dependent on engagement of the $\alpha \mathrm{m} \beta 2$ integrin (130). Another PIII class SVMP, jararhagin, was shown to stimulate production of inflammatory mediators by murine macrophages, increasing mRNA translation for IL-6, TNF, and IL-1 (131). This SVMP also up-regulated gene expression of IL-8, IL-11, CXCL2, IL-1 $\beta$, IL6 , and mammalian matrix metalloproteases (MMPs)-1 and 10 (132). Regarding activities on endothelial cells, berythractivase, a non-hemorrhagic PIII class SVMP, has been reported to induce an inflammatory state in these cells by upregulating expression of adhesion molecules, such as ICAM-1 and E-selectin, and inducing release of IL-8, NO, and vWF (133).

In addition, the ability of $\mathrm{BaPl}$ to activate classic and alternative complement pathways, generating the chemotactic C5a factor, has been demonstrated. Accordingly, BaP1-treated serum developed the ability to induce chemotaxis of neutrophils in vitro (100). In line with these findings, participation of the complement system in the migration of inflammatory leukocytes into the site of injection of PI class SVMP from B. atrox snake venom has also been demonstrated (70).

In addition to pro-inflammatory activities, SVMPs can activate platelet functions by diverse mechanisms, including activation of the coagulation cascade, by inducing activation of prothrombin, vWF, factor X, and II and the complement cascade (C5a and C3a release), as well as engagement of platelet glycoprotein receptors. Prothrombin activating SVMPs are classified into A-D groups of prothrombin activators with the ability to cleave prothrombin, generating meizothrombin, which is then converted into $\alpha$-thrombin, a potent mediator of microvascular thrombosis and inflammation (134-136). The first group of these factors comprise SVMPs isolated from Bothrops snake venoms of both PI and PIII classes. Examples 
include bothrojaractivase, isolated from $B$. jararaca snake venom (120), insularinase A from $B$. insularis (119), cotiarinase from $B$. cotiara (121), and berythractivase, isolated from B. erythromelas (118). Of note, besides inducing release of vWF, berythractivase has also been demonstrated to upregulate tissue factor (TF) expression in endothelial cells in vitro, displaying potent systemic thrombogenic activity, which in association with a generation of thrombin and inflammatory mediators, may contribute to thromboinflammation by favoring formation of systemic microthrombi (137).

SVMPs that are able to activate factor $\mathrm{X}$ have also been isolated from viper snake venoms and encompass P-III class enzymes (138). Factors II and X, found in the plasma as zymogens, can be activated by SVMPs via proteolytic cleavage of specific peptide bond sites, resulting in blood clotting (139). In this sense, the SVMP moojenactivase (MooA) induces human plasma clotting in vitro by activating coagulation factors II (prothrombin) and $\mathrm{X}$, which in turn generate $\alpha$-thrombin and factor Xa, respectively. Additionally, MooA induces aggregation of washed platelets and expression of TF on the membrane surface of peripheral blood mononuclear cells (122). Tissue factor has been reported to be involved in both thrombosis and inflammation, and several mediators, including pro-inflammatory cytokines and thrombin, induce its expression $(140,141)$. In this context, MooA is another promising candidate as an inducer of thromboinflammation during Bothrops envenomation.

Platelet adhesion and aggregation may be initiated by engaging specific membrane receptors that lead to platelet activation. Botrocetin, an SVMP isolated from $B$. jararaca snake venom, is an example of a potent activator of platelet function because it induces vWF- and platelet glycoprotein Ib (GPIb)dependent platelet agglutination in vitro, resulting in platelet agglutination. Botrocetin appears to act in a two-step manner; first, it binds to vWF, forming a complex, which then binds to GPIb, causing platelet agglutination (142, 143). Moreover, other SVMPs, such as jararhagin, a PIII class SVMP, jaracetin, a differentially processed form of jararhagin lacking the catalytic domain, and the one-chain botrocetin, which corresponds to the disintegrin and cysteine-rich domains of jararhagin from $B$. jararaca snake venom, are able to activate vWF and its binding to platelet GP Ib-IX-V $(144,145)$. Interestingly, both jararhagin and jaracetin, but not botrocetin, are able to block the adhesion of collagen to platelet integrin $\alpha 2 \beta 1$ (145). These data demonstrate that SVMPs of the same class can activate different molecular targets to induce their actions on platelets.

The diversity and abundance of SVMPs in Viperidae snake venoms and their ability to induce inflammatory and pro coagulation events make them one the most promising toxin families for studies related to the characterization of venominduced thromboinflammation.

\section{Snake Venom C-type Lectins}

The C-type lectin family comprises proteins that recognize and bind carbohydrates in a $\mathrm{Ca}^{2+}$-dependent manner $(146,147)$ and non-sugar-binding snake venom C-type lectin-related proteins (SV-CLRPs), also called snaclecs $(148,149)$. These proteins exhibit the C-type lectin domain (CTLD) but differ from it in a long loop that either contributes to the sugar-binding site or is expanded into a loop-swapping heterodimerization domain between two CLRP subunits. SV-CLRPs connect with a multitude of molecules implicated in hemostasis that are present on endothelial cells, coagulation factors, and receptors of platelets, having a role in thrombus formation and inflammation (150).

With regard to inflammation, interaction of SV-CLRPs with immune cells, such as peripheral mononuclear cells and neutrophils, has been shown with the galactose-binding lectins from the venoms of $B$. jararacussu and $B$. leucurus snakes $(82,151)$. In addition to inducing edema and increasing vascular permeability in murine experimental models (152), BJcul from $B$. jararacussu venom has been demonstrated to stimulate phagocytosis of zymozan particles by macrophages and increase the lysosomal volume in neutrophils. In addition, BJcuL delays apoptosis of neutrophils and stimulates peripheral mononuclear cells to produce superoxide anions and hydrogen peroxide $(82,151)$. In human monocytes, BJcul up-regulates expression of antigen presentation molecules and enhances TNF- $\alpha$, GM-CSF, and IL-6 synthesis by macrophages. Under inflammatory conditions, BjcuL induces macrophages into the M1 state of functional activation and indirectly stimulates $\mathrm{T}$ cells to produce TNF- $\alpha$, IFN- $\gamma$, and IL- 6 in the presence of LPS (151, 153). Moreover, galatrox, a C-type lectin from $B$. atrox snake venom, has been reported to interact with LacNAc-bearing glycans on neutrophils and macrophages, as well as with extracellular matrix proteins, leading to the release of pro-inflammatory mediators, such as IL-6, TNF$\alpha$, and keratinocyte-derived chemokine (KC). In an in vivo experimental model, galatrox induced marked neutrophil migration and was shown to induce release of pro-inflammatory cytokines IL- $1 \alpha$ and IL- 6 in the peritoneal cavity of mice. These effects were mediated by activation of the TLR4MyD88 signaling pathway by the galatrox carbohydrate domain (154).

Homeostasis of blood coagulation depends on platelet activation, a process closely linked to inflammation (4). In this context, SV-CLRPs have been shown a broad and partially overlap with the platelet receptor-binding spectrum (155-157). Activation of platelets by SV-CLRPs occurs in a non-enzymatic manner, leading to inadequate thrombus formation and vessel occlusion. Conversely, some SV-CLRPs inhibit binding of the physiological ligands, antagonistically preventing the receptor from eliciting signals and resulting in severe bleeding. SV-CLRPs reported to agglutinate platelets via binding to GPIb include agglucetin from Agkistrodon acutus venom $(158,159)$, alboaggregin-B from the Viperidae venom Trimeresurus albolabris (160-162), mucrocetin and mucetin from Trimeresurus mucrosquamatus $(163,164)$, and jerdonuxin from Trimeresurus/Protobothrops jerdonii (164, 165). Agglucetin and alboaggregin- $\mathrm{B}$ also bind vWF receptor, but neither increase intracellular $\mathrm{Ca}^{2+}$ ions nor trigger platelet degranulation (158, 159). This suggests that platelets can be cross-linked and agglutinated by SV-CLRP-mediated GPIb multimerization, whereas a physiological agonist (vWF) elicits an active signaling process. Stejnulxin from Trimeresurus stejnegeri venom has been reported to activate platelets via GPVI $(156,166)$, a receptor for collagen on the platelet surface. However, EMS16 from Echis multisquamatus (166-169) binds to the collagen receptor 
of platelets, integrin $\alpha 2 \beta 1$, inhibiting the binding of collagen (170-172). Of note, $\alpha 2 \beta 1$ has been hypothesized to be responsible for strong adhesion of platelets to collagen, an event necessary for thrombus formation (172).

A platelet activation receptor, C-type lectin-like receptor 2 (CLEC-2), has been recognized as a platelet receptor activated by proteins isolated from snake venoms as evidenced by rhodocytin/aggretin (SV-CLRPs) from Calloselasma rhodostoma venom (173). CLEC-2 is expressed in immunocompetent cells, such as dendritic cells, monocytes, and neutrophils, and strongly expressed in platelets/megakaryocytes $(174,175)$. This receptor triggers strong activation of platelets through the tyrosine kinase dependent pathway. CLEC-2 has a single YxxL motif in its cytoplasmic tail, called hemi-ITAM because it resembles ITAM (tyrosine-based activation motif, YxxL-[X]10-12-YxxL), which has two YxxL motifs. ITAM is a signaling motif found in immune receptors, such as the T-cell receptor and the platelet collagen receptor GPVI-FcRc-chain complex. Engagement of CLEC-2 or GPVI triggers a signaling cascade culminating in platelet activation/aggregation (176) and thrombus formation (172, 177, 178).

Together, the above information evidences the high selectivity of various SV-CLRPs to platelet receptors, which are involved in activation of both platelet aggregation and inflammatory cascades, such as vWF and collagen receptor, known to be generated upon tissue injury.

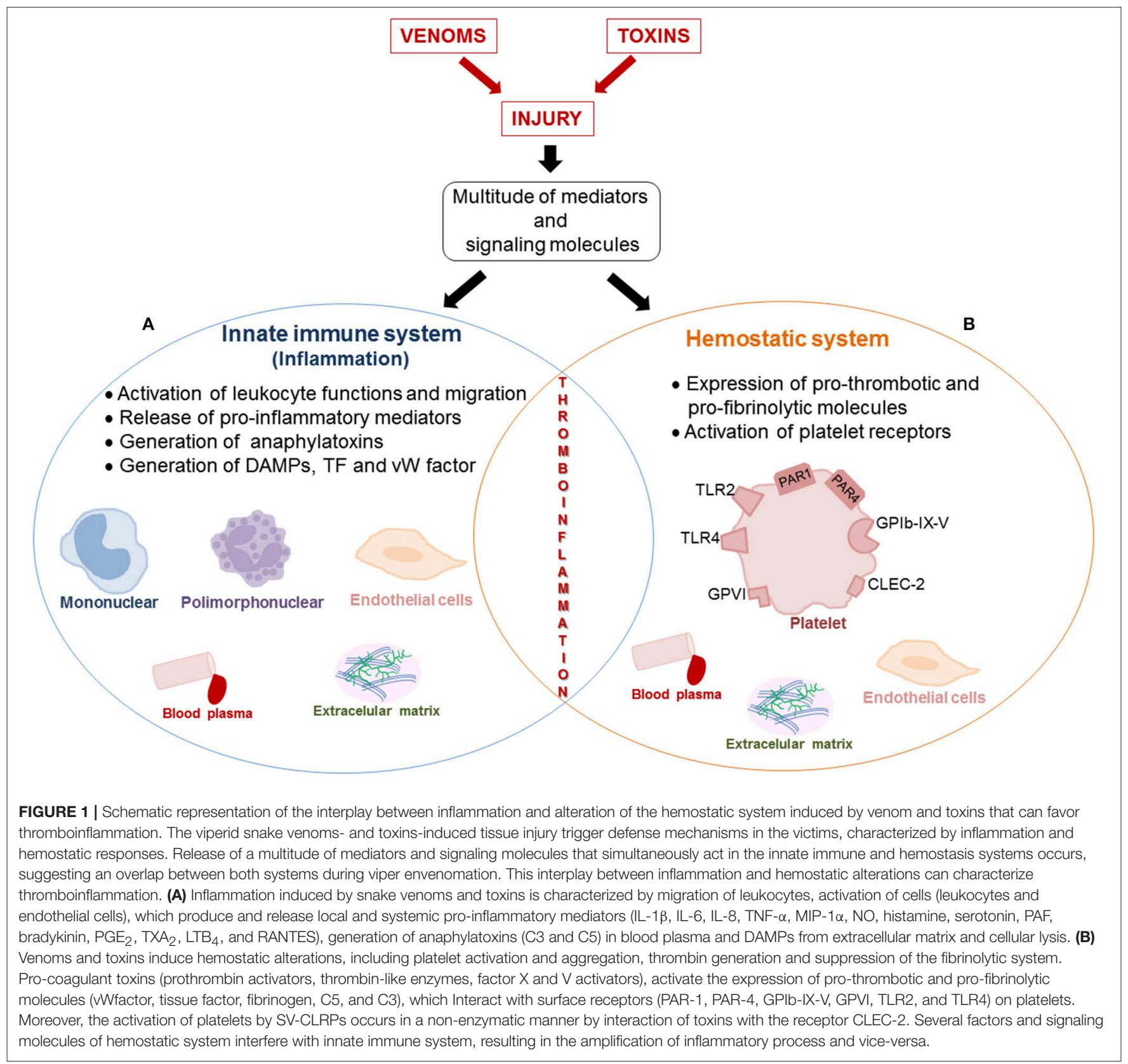




\section{CONCLUDING REMARKS}

The inflammatory response is closely associated with the onset of local and systemic toxicity induced by viperid venoms and their toxins. To date, the mechanisms underlying inflammation and blood coagulation induced by Viperidae venoms have been viewed as distinct processes. However, studies on the mechanisms related to inflammation and hemostatic alterations induced by viperid envenomation have evidenced participation of a multitude of mediators and signaling molecules that can simultaneously act in the innate immune and hemostasis systems. Toxins involved in these effects have also been identified, and for some of them, molecular mechanisms of action have been revealed. Therefore, the available information strongly suggests that an overlap between inflammation and hemostasis alterations, regarded as thromboinflammation, may occur during envenomation by viperid snakes (Figure 1). In this context, proinflammatory cytokines, which increase in production during viper venom-induced inflammation, have been demonstrated to induce hemostatic alterations, including platelet activation and aggregation, endothelial activation, thrombin generation, and suppression of the fibrinolytic system in several pathological conditions. Reciprocally, components of the hemostatic system also interfere with the immune system, leading to inflammation and amplifying this process. Moreover, besides pro-inflammatory activities, some Bothrops sp. SVMPs have been described to activate the expression of pro-thrombotic and pro-fibrinolytic molecules by endothelial cells and leukocytes, thus enhancing the coagulopathy seen in viperid snakebites. Similarly, SVCLRPs activate platelet receptors, which are involved in both platelet aggregation and inflammation cascades. Therefore, SVMPs and SV-CRLPs are venom components selective for

\section{REFERENCES}

1. Jackson SP, Darbousset R, Schoenwaelder SM. Thromboinflammation: challenges of therapeutically targeting coagulation and other host defense mechanisms. Blood. (2019) 133:906-18. doi: 10.1182/blood-2018-11-882993

2. Gragnano F, Sperlongano S, Golia E, Natale F, Bianchi R, Crisci M, et al. The role of von Willebrand factor in vascular inflammation: from pathogenesis to targeted therapy. Mediators Inflamm. (2017) 2017:5620314. doi: $10.1155 / 2017 / 5620314$

3. Chauhan AK, Kisuka J, Brill A, Walsh MT, Scheiflinger F, Wagner DD. ADAMTS13: a new link between thrombosis and inflammation. J Exp Med. (2008) 205:2065-74. doi: 10.1084/jem.20080130

4. Massberg S, Grahl L, von Bruehl ML, Manukyan D, Pfeiler S, Goosmann C, et al. Reciprocal coupling of coagulation and innate immunity via neutrophil serine proteases. Nat Med. (2010) 16:887-96. doi: 10.1038/nm.2184

5. Ekdahl KN, Teramura Y, Hamad OA, Asif S, Duehrkop C, Fromell K, et al. Dangerous liaisons: complemente, coagulation, and kallikrein/kinin crosstalk act as linchpin in the events leading to thromboinflammation. Immunol Rev. (2016) 274:245-69. doi: 10.1111/imr.12471

6. Frontera JA, Provencio JJ, Sehba FA, McIntyre TM, Nowacki AS, Gordon $\mathrm{E}$, et al. The role of platelet activation and inflammation in early brain injury following subarachnoid hemorrhage. Neurocrit Care. (2017) 26:48-57. doi: 10.1007/s12028-016-0292-4

7. Harrison P. Platelet function analysis. Blood Rev. (2005) 19:111-23. doi: 10.1016/j.blre.2004.05.002 the activation of platelet functions and thrombus formation and are potent inducers of inflammation. This additionally argues for development of thromboinflammation during viperid envenomation. However, despite the evidence presented herein, the potential interplay between inflammation and hemostatic alterations induced by viperid snake venoms has never been reported. Therefore, comprehensive studies on the crosstalk between disturbances of hemostasis and inflammatory processes displayed by viperid snake envenomation are stressed. The impact of thromboinflammation on the toxic effects induced by Viperidae venoms also requires further investigation. Finally, we believe that this new aspect on the research of snake venom activities may bring renewed understanding of the complex pathology triggered by viperid snake venoms and toxins and may allow the discovery of new therapeutic targets and procedures to confront envenomation mortality and morbidity.

\section{AUTHOR CONTRIBUTIONS}

CT, CF, EL, and AC-T contributed to conception and design of the review, wrote the first draft of the review, contributed to text revision, read and approved the submitted version.

\section{FUNDING}

This work was supported by a research grant from FAPESP, Brazil (Grant 2015/50040-4). CT and AC-T are recipients of CNPq-PQ grant numbers 307379/2016-7 and 303197/2017-0, respectively. $\mathrm{CT}, \mathrm{AC}-\mathrm{T}$, and $\mathrm{CF}$ are recipients of Fundação Butantan-PQ grants, and EL is a recipient of a Post-Doctoral fellowship from FAPESP, Brazil (Grant 2015/24701-3).

8. Wang Y, Andrews M, Yang Y, Lang S, Jin JW, Cameron-Vendrig A, et al. Platelets in thrombosis and hemostasis: old topic with new mechanisms. Cardiovasc Hematol Disord Drug Targets. (2012) 12:126-32. doi: 10.2174/1871529X11202020126

9. Heijnen $H$, van der Sluijs P. Platelet secretory behaviour: as diverse as the granules ... or not? J Thromb Haemost. (2015) 13:2141-51. doi: $10.1111 /$ jth. 13147

10. Kahn ML, Zheng YW, Huang W, Bigornia V, Zeng D, Moff S, et al. A dual thrombin receptor system for platelet activation. Nature. (1998) 394:690-4. doi: $10.1038 / 29325$

11. Kahn ML, Nakanishi-Matsui M, Shapiro MJ, Ishihara H, Coughlin SR. Protease-activated receptors 1 and 4 mediate activation of human platelets by thrombin. J Clin Invest. (1999) 103:879-87. doi: 10.1172/JCI6042

12. Huntington JA. Molecular recognition mechanisms of thrombin. J Thromb Haemost. (2005) 3:1861-72. doi: 10.1111/j.1538-7836.2005.01363.x

13. Furuhashi I, Abe K, Sato T, Inoue H. Thrombin-stimulated proliferation of cultured human synovial fibroblasts through proteolytic activation of proteinase-activated receptor-1. J Pharmacol Sci. (2008)108:104-11. doi: 10.1254/jphs.08126FP

14. Hsieh HL, Tung WH, Wu CY, Wang HH, Lin CC, Wang TS, et al. Thrombin induces EGF receptor expression and cell proliferation via a $\mathrm{PKC}($ delta $/ \mathrm{c}$ Src-dependent pathway in vascular smooth muscle cells. Arterioscler Thromb Vasc Biol. (2009) 29:1594-601. doi: 10.1161/ATVBAHA.109.185801

15. Kastl SP, Speidl WS, Katsaros KM, Kaun C, Rega G, Assadian A, et al. Thrombin induces the expression of oncostatin M via AP-1 activation in 
human macrophages: a link between coagulation and inflammation. Blood. (2009) 114:2812-8. doi: 10.1182/blood-2009-01-200915

16. Wang $\mathrm{Y}$, Gallant RC, Ni H. Extracellular matrix proteins in the regulation of thrombus formation. Curr Opin Hematol. (2016) 23:280-7. doi: 10.1097/MOH.0000000000000237

17. Clemetson KJ, Clemetson JM. Chapter 9: platelet receptors. In: Michelson AD, editor. Platelets. 3rd ed. Amsterdam: Academic Press/Elsevier (2012). p. 169-94. doi: 10.1016/B978-0-12-387837-3.00009-2

18. Ni H, Freedman J. Platelets in hemostasis and thrombosis: role of integrins and their ligands. Transfus Apher Sci. (2003) 28:257-64. doi: 10.1016/S1473-0502(03)00044-2

19. Bergmeier W, Hynes RO. Extracellular matrix proteins in hemostasis and thrombosis. Cold Spring Harb Perspect Biol. (2012) 4:a005132. doi: 10.1101/cshperspect.a005132

20. Patel S, Huang YW, Reheman A, Pluthero FG, Chaturvedi S, Mukovozov IM, et al. The cell motility modulator Slit2 is a potent inhibitor of platelet function. Circulation. (2012) 126:1385-95. doi: 10.1161/CIRCULATIONAHA.112.105452

21. Vendrig AC, Reheman A, Siraj MA, Xu XR, Wang Y, Lei X, et al. Glucagon-like peptide 1 receptor activation attenuates platelet aggregation and thrombosis. Diabetes. (2016) 65:1714-23. doi: 10.2337/db15-1141

22. Ruggeri ZM, Jackson SP. Chapter 20: platelet thrombus formation in flowing blood. In: Michelson AD, editor. Platelets. 3rd ed. Amsterdam: Academic Press/Elsevier (2013). p. 399-424. doi: 10.1016/B978-0-12-387837-3.00020-1

23. Jackson SP. The growing complexity of platelet aggregation. Blood. (2007) 109:5087-95. doi: 10.1182/blood-2006-12-027698

24. Semple JW, Italiano JE Jr, Freedman J. Platelets and the immune continuum. Nat Rev Immunol. (2011) 11:264-74. doi: 10.1038/nri2956

25. Aslam R, Speck ER, Kim M, Crow AR, Bang KW, Nestel FP, et al. Platelet Toll-like receptor expression modulates lipopolysaccharide-induced thrombocytopenia and tumor necrosis factor-alpha production in vivo. Blood. (2006) 107:637-41. doi: 10.1182/blood-2005-06-2202

26. Zhang G, Han J, Welch EJ, Ye RD, Voyno-Yasenetskaya TA, Malik AB, et al. Lipopolysaccharide stimulates platelet secretion and potentiates platelet aggregation via TLR4/ MyD88 and the CGMP-dependent protein kinase pathway. J Immunol. (2009) 182:7997-8004. doi: 10.4049/jimmunol.0802884

27. Clark SR, Ma AC, Tavener SA, McDonald B, Goodarzi Z, Kelly MM, et al. Platelet TLR4 activates neutrophil extracellular traps to ensnare bacteria in septic blood. Nat Med. (2007) 13:463-9. doi: 10.1038/nm1565

28. Martinod K, Wagner DD. Thrombosis: tangled up in NETs. Blood. (2014) 123:2768-76. doi: 10.1182/blood-2013-10-463646

29. Engelmann B, Massberg S. Thrombosis as an intravascular effector of innate immunity. Nat Rev Immunol. (2013) 13:34-45. doi: 10.1038/nri3345

30. Xu XR, Zhang D, Oswald BE, Carrim N, Wang X, Hou Y, et al. Platelets are versatilecells: new discoveries in hemostasis, thrombosis, immune responses, tumor metastasis and beyond. Crit Ver Clin Lab Sci. (2016) 53:409-30. doi: $10.1080 / 10408363.2016 .1200008$

31. WHO Rabies and Envenomings. A Neglected Public Health Issue. (2007) Available online at: http://whqlibdoc.who.int/publications/2007/ 9789241563482_eng.pdf

32. WHO Technical Report Series, No. 1004 (2017). Annex 5/Appendix 1 Worldwide Distribution of Medically Important Venomous Snakes. Available online at: https://www.who.int/bloodproducts/AntivenomGLrevWHO_ TRS_1004_web_Annex_5.pdf

33. Uetz P, Hosek J. (2014) The Reptile Database. Available online at: http://www. reptile-database.org

34. Alencar LRV, Quental TB, Grazziotin, FG, Alfaro ML, Martins M, Venzon $M$, et al. Phylogenetic relationships, time divergence and shifts in speciation rates. Mol Phylogenet Evol. (2016) 105:50-62. doi: 10.1016/j.ympev.2016.07.029

35. Warrell DA. Snakebites in Central and South America: epidemiology, clinical features, and clinical management. In: Campbell JA, Lamar WW, editors. The Venomous Reptiles of the Western Hemisphere. Ithaca, NY: Comstock Publishers/Cornell University Press (2004). p. 709-61.

36. Warrell DA. Snake bite. Lancet. (2010) 375:77-88. doi: 10.1016/S0140-6736(09)61754-2

37. Thomas L, Chausson N, Uzan J, Kaidomar S, Vignes R, Plumelle Y, et al. Thrombotic stroke following snake bites by the 'Fer-de-Lance' Bothrops lanceolatus in Martinique despite antivenom treatment: a report of three recent cases. Toxicon. (2006) 48:23-8. doi: 10.1016/j.toxicon.2006.04.007

38. Malbranque S, Piercecchi-Marti MD, Thomas L, Barbey C, Courcier D, Bucher B, et al. Fatal diffuse thrombotic microangiopathy after a bite by the 'Fer-de-Lance' pit viper (Bothrops lanceolatus) of Martinique. Am J Trop Med Hyg. (2008) 78:856-61. doi: 10.4269/ajtmh.2008.78.856

39. Du XY, Sim DS, Lee WH, Zhang Y. Blood cells as targets of snake toxins. Blood Cells Mol Dis. (2006) 36:414-21. doi: 10.1016/j.bcmd.2006.03.001

40. Kini RM. Toxins in thrombosis and haemostasis: potential beyond imagination. J Thromb Haemost. (2011) 9 (Suppl. 1):195-208. doi: $10.1111 / j .1538-7836.2011 .04279 . x$

41. Slagboom J, Kool J, Harrison RA, Casewell NR. Haemotoxic snake venoms: their functional activity, impact on snakebite victims and pharmaceutical promise. Br J Haematol. (2017) 177:947-59. doi: 10.1111/bjh.14591

42. Maruyama M, Kamiguti AS, Cardoso JL, Sano-Martins IS, Chudzinski AM, Santoro ML, et al. Studies on blood coagulation and fibrinolysis in patients bitten by Bothrops jararaca (jararaca). Thromb Haemost. (1990) 63:449-53. doi: $10.1055 / \mathrm{s}-0038-1645064$

43. de Queiroz MR, de Sousa BB, da Cunha Pereira DF, Mamede CCN, Matias MS, de Morais NCG, et al. The role of platelets in hemostasis and the effects of snake venom toxins on platelet function. Toxicon. (2017) 133:33-47. doi: 10.1016/j.toxicon.2017.04.013

44. Matsui T, Hamako J, Titani K. Structure and function of snake venom proteins affecting platelet plug formation. Toxins. (2010) 2:10-23. doi: 10.3390/toxins 2010010

45. Rosa JG, de Albuquerque CZ, Mattaraia VGM, Santoro ML. Comparative study of platelet aggregation and secretion induced by Bothrops jararaca snake venom and thrombin. Toxicon. (2019) 159:50-60. doi: 10.1016/j.toxicon.2019.01.003

46. Kamiguti AS, Matsunaga S, Spir M, Sano-Martins IS, Nahas L. Alterations of the blood coagulation system after accidental human inoculation by Bothrops jararaca venom. Braz J Med Biol Res. (1986) 19:199-204.

47. Jorge MT, Cardoso JL, Castro SC, Ribeiro L, Franca FO, et al. A randomized 'blinded' comparison of two doses of antivenom in the treatment of Bothrops envenoming in São Paulo, Brazil. Trans R Soc Trop Med Hyg. (1995) 89:1114. doi: 10.1016/0035-9203(95)90678-9

48. Yamashita KM, Alves AF, Barbaro KC, Santoro ML. Bothrops jararaca venom metalloproteinases are essential for coagulopathy and increase plasma tissue factor levels during envenomation. PLoS Negl Trop Dis. (2014) 8:e2814. doi: 10.1371/journal.pntd.0002814

49. Maduwage K, Isbister GK. Current treatment for venom-induced consumption coagulopathy resulting from snakebite. PLoS Negl Trop Dis. (2014) 8:e3220. doi: 10.1371/journal.pntd.0003220

50. Barrantes A, Solis V, Bolanos R. Alterations in the coagulation mechanisms of patients bitten by Bothrops asper (Terciopelo). Toxicon. (1985) 23:399-407. doi: 10.1016/0041-0101(85)90024-8

51. Otero-Patino R, Segura A, Herrera M, Angulo Y, Leon G, Gutiérrez JM, et al. Comparative study of the efficacy and safety of two polyvalent, caprylic acid fractionated [IgG and F(ab9)2] antivenoms, in Bothrops asper bites in Colombia. Toxicon. (2012) 59:344-55. doi: 10.1016/j.toxicon.2011. 11.017

52. Sano-Martins IS, Tomy SC, Campolina D, Dias MB, de Castro SC, de Sousae-Silva MC, et al. Coagulopathy following lethal and non-lethal envenoming of humans by the South American rattlesnake (Crotalus durissus) in Brazil. QJM. (2001) 94:551-9. doi: 10.1093/qjmed/94.10.551

53. Kamiguti AS, Cardoso JL. Haemostatic changes caused by the venoms of South American snakes. Toxicon. (1989) 27:955-63. doi: 10.1016/0041-0101(89)90146-3

54. Li QB, Huang GW, Kinjoh K, Nakamura M, Kosugi T. Hematological studies on DIC-like findings observed in patients with snakebite in south China. Toxicon. (2001) 39:943-8. doi: 10.1016/S0041-0101(00)00232-4

55. Rosenfeld G. Symptomatology, pathology and treatment of snakebites in South America. In: Bucherk W, Buckley EE, editors. Venomous Animal and Their Venoms, Vol. 2. New York, NY: Academic Press (1971). p. 345-403. doi: 10.1016/B978-0-12-138902-4.50021-0

56. Sawai, Y. Studies on snakebites in the Asian areas. In: Eaker D, Wadstrom T, editors. Natural Toxins. Oxford: Pergamon Press (1980). p. 25-32. doi: 10.1016/B978-0-08-024952-0.50007-7 
57. Cardoso JLC, Fan HW, Franca FOS, Jorge MT, Leite RP, Nishioka SA, et al. Randomized comparative trial of three antivenoms in the treatment of envenoming by lance-headed vipers (Bothrops jararaca) in São Paulo, Brazil. Q J Med. (1993) 86:315-25.

58. Otero R, Gutierrez JM, Mesa MB, Duque E, Rodriguez O, Arango JL, et al. Complications of Bothrops, Porthidium, and Bothriechis snakebites in Colombia. A clinical and epidemiological study of 39 cases attended in a university hospital. Toxicon. (2002) 40:1107-14. doi: 10.1016/S0041-0101(02)00104-6

59. Jorge MT, Ribeiro LA, O'Connell JL. Prognostic factors for amputation in the case of envenoming by snakes of the Bothrops genus (Viperidae). Ann Trop Med Parasitol. (1999) 93:401-8. doi: 10.1080/00034989958393

60. Lomonte B, Lundgren J, Johansson B, Bagge U. The dynamics of local tissue damage induced by Bothrops asper snake venom and myotoxin II on the mouse cremaster muscle: an intravital and electron microscopic study. Toxicon. (1994) 32:41-55. doi: 10.1016/0041-0101(94)90020-5

61. Trebien HA, Calixto JB. Pharmacological evaluation of rat paw odema induced by Bothrops jararaca venom. Agents Actions. (1989) 26:292-300. doi: 10.1007/BF01967293

62. Nascimento NG, Sampaio MC, Amaral Olivo R, Teixeira C. Contribution of mast cells to the oedema induced by Bothrops moojeni snake venom and a pharmacological assessment of the inflammatory mediators involved. Toxicon. (2010) 55:343-52. doi: 10.1016/j.toxicon.2009.08.009

63. Bonavita AG, da Costa AS, Pires AL, Neves-Ferreira AG, Perales J, Cordeiro RS, et al. Contribution of mast cells and snake venom metalloproteinases to the hyperalgesia induced by Bothrops jararaca venom in rats. Toxicon. (2006) 47:885-93. doi: 10.1016/j.toxicon.2006.02.017

64. Teixeira C, Cury Y, Oga S, Jancar S. Hyperalgesia induced by Bothrops jararaca venom in rats: role of eicosanoids and platelet activating fator (PAF). Toxicon. (1994) 32:419-26. doi: 10.1016/0041-0101(94)90293-3

65. Olivo RA, Teixeira C, Wallace JL, Gutiérrez JM, Zamuner SR. Role of cyclooxigenases in edema-forming activity of bothropic venoms. Toxicon. (2007) 49:670-7. doi: 10.1016/j.toxicon.2006.11.006

66. Moreira V, Dos-Santos MC, Nascimento NG, Silva HB, Fernandes CM, D'Império Lima MR, et al. Local inflammatory events induced by Bothrops atrox snake venom. Toxicon. (2012) 60:12-20. doi: 10.1016/j.toxicon.2012.03.004

67. Gonçalves LRC, Mariano M. Local hemorrhage induced by Bothrops jararaca venom: relationship to neurogenic inflammation. Mediators Inflamm. (2000) 9:101-7. doi: 10.1080/096293500411569

68. Barbosa AM, Amaral RO, Teixeira CFP, Hyslop S, Cogo JC. Pharmacological characterization of mouse hind paw oedema induced by Bothrops insularis (jararaca ilhoa) snake venom. Toxicon. (2003) 42:515-23. doi: 10.1016/S0041-0101(03)00230-7

69. Chaves F, Barbosa M, Gutierrez JM. Pharmacological study of edema induced by venom of the snake Bothrops asper (Terciopelo) in mice. Toxicon. (1995) 33:31-9. doi: 10.1016/0041-0101(94)00135-U

70. Rodrigues FG, Petretski JH, Kanashiro MM, Lemos L, da Silva WD, Kipnis TL. The complement system is involved in acute inflammation, but not in the hemorrhage produced by Bothrops atrox snake venom low molecular mass proteinase. Mol Immunol. (2004) 40:1149-56. doi: 10.1016/j.molimm.2003.11.032

71. Piede-Queiroz G, Magnoli FC, Portaro FC, Serrano SM, Lopes AS, Paes Leme $\mathrm{M}$, et al. P-1 snake venom metalloproteinase is able to activate the complement system by direct cleavage of central components of the cascade. PLoS Negl Trop Dis. (2013) 7:e2519. doi: 10.1371/journal.pntd.0002519

72. Piede-Queiroz G, Furtado MEF, Filgueiras CF, Pessoa LA, SpadaforaFerreira M, van den Berg CW, et al. Human complement activation and anaphylatoxins generation induced by snake venom toxins from Bothrops genus. Mol Immunol. (2010) 47:2537-44. doi: 10.1016/j.molimm.2010.07.003

73. Stone SF, Isbister GK, Shahmy S, Mohamed F, Abeysinghe C, Karunathilake $\mathrm{H}$, et al. Immune response to snake envenoming and treatment with antivenom; complement activation, cytokine production and mast cell degranulation. PLoS Negl Trop Dis. (2013) 7:e2326. doi: 10.1371/journal.pntd.0002326

74. Tambourgi DV, van den Berg CW. Animal venoms/toxins and the complement system. Mol Immunol. (2014) 61:153-62. doi: 10.1016/j.molimm.2014.06.020
75. Mora J, Mora R, Lomonte B, Gutiérrez JM. Effects of Bothrops asper snake venom on lymphatic vessels: insights into a hidden aspect of envenomation. PLoS Negl Trop Dis. (2008) 2:e318. doi: 10.1371/journal.pntd.0000318

76. Teixeira C, Cury Y, Moreira V, Picolob G, Chaves F. Inflammation induced by Bothrops asper venom. Toxicon. (2009) 54:988-97. doi: 10.1016/j.toxicon.2009.03.019

77. Barros SF, Friedlanskaia I, Petricevich VL, Kipnis TL. Local inflammation, lethality and cytokine release in mice injected with Bothrops atrox venom. Mediators Inflamm. (1998) 7:339-46. doi: 10.1080/09629359890866

78. Guimarães AQ, Cruz-Höfling MA, Ferreira de Araújo PM, Bon C, Lôbo de Araújo A. Pharmacological and histopathological characterization of Bothrops lanceolatus (Fer de lance) venom-induced edema. Inflamm Res. (2004) 53:284-91. doi: 10.1007/s00011-004-1258-0

79. Gutiérrez JM, Rucavado A, Chaves F, Díaz C, Escalante T. Experimental pathology of local tissue damage induced by Bothrops asper snake venom. Toxicon. (2009) 54:958-75. doi: 10.1016/j.toxicon.2009.01.038

80. Farsky SH, Costa-Cruz JWM, Cury Y, Teixeira CF. Leukocyte response induced by Bothrops jararaca crude venom: in vivo and in vitro studies. Toxicon. (1997) 35:185-93. doi: 10.1016/S0041-0101(96)00135-3

81. Wanderley CW, Silva CM, Wong DV, Ximenes RM, Morelo DF, Cosker $\mathrm{F}$, et al. Bothrops jararacussu snake venom induces a local inflammatory response in a prostanoid and neutrophil-dependent manner. Toxicon. (2014) 90:134-47. doi: 10.1016/j.toxicon.2014.08.001

82. Elifio-Esposito SI, Tomazeli L, Schwartz C, Gimenez AP, Fugii GM, Fernandes LC, et al. Human neutrophil migration and activation by BJcuL, a galactose binding lectin purified from Bothrops jararacussu venom. BMC Immunol. (2011) 12:10. doi: 10.1186/1471-2172-12-10

83. Elifio-Esposito SI, Hess PL, Moreno AN, Lopes-Ferreira M, Ricart CAO, Souza M, et al. A C-Type lectin from Bothrops jararacussu venom can adhere to extracellular matrix proteins and induce the rolling of leukocytes. J Venom Anim Toxins Incl Trop Dis. (2007) 13:782-99. doi: 10.1590/S1678-91992007000400009

84. Zamuner SR, Teixeira C. Cell adhesion molecules involved in the leukocyte recruitment induced by venom of the snake Bothrops jararaca. Mediators Inflamm. (2002) 11:351-7. doi: 10.1080/0962935021000051548

85. Flores CA, Zappellini A, Prado-Franceschi J. Lipoxygenase-derived mediators may be involved in in vivo neutrophil migration induced by Bothrops erytromelas and Bothrops alternatus venoms. Toxicon. (1993) 31:1551-9. doi: 10.1016/0041-0101(93)90339-K

86. Zamuner SR, Zuliani JP, Fernandes CM, Gutiérrez JM, Teixeira CFP. Inflammation induced by Bothrops asper venom: release of proinflammatory cytokines and eicosanoids and role of adhesion molecules in leukocyte infiltration. Toxicon. (2005) 46:806-13. doi: 10.1016/j.toxicon.2005.08.011

87. Arend WP, Gabay C. Cytokines in the rheumatic diseases. Rheum Dis Clin North Am. (2004) 30:41-67. doi: 10.1016/S0889-857X(03)00115-7

88. Escocard RC, Kanashiro MM, Petretski JH, Azevedo-Silva J, Queiroz de Carvalho EC. Neutrophils regulate the expression of cytokines, chemokines and nitric oxide synthase/nitric oxide in mice injected with Bothrops atrox venom. Immunobiology. (2006) 211:37-43. doi: 10.1016/j.imbio.2005. 08.003

89. Delafontaine M, Villas-Boas IM, Mathieu L, Josset P, Blomet J, Tambourgi DV. Enzymatic and pro-inflammatory activities of Bothrops lanceolatus venom: relevance for envenomation. Toxins. (2017) A9:E244. doi: 10.3390/toxins9080244

90. Zoccal KF, Ferreira GZ, Prado MKB, Gardinassi LG, Sampaio SV, Faccioli LH. LTB4 and PGE2 modulate the release of MIP- $1 \alpha$ and IL-1 $\beta$ by cells stimulated with Bothrops snake venoms. Toxicon. (2018) 150:289-96. doi: 10.1016/j.toxicon.2018.06.066

91. Echeverría S, Leiguez E, Guijas C, do Nascimento NG, Acosta O, Teixeira C, et al. Evaluation of pro-inflammatory events induced by Bothrops alternatus snake venom. Chem Biol Interact. (2018) 281:24-31. doi: 10.1016/j.cbi.2017.12.022

92. Rucavado A, Nicolau CA, Escalante T, Kim J, Herrera C, Gutiérrez JM, et al. Viperid envenomation wound exudate contributes to increased vascular permeability via a DAMPs/TLR-4 mediated pathway. Toxins. (2016) 8:349. doi: 10.3390/toxins 8120349

93. Petricevich VL, Teixeira CF, Tambourgi DV, Gutiérrez JM. Increments in serum cytokine and nitric oxide levels in mice injected with Bothrops 
asper and Bothrops jararaca snake venoms. Toxicon. (2000) 38:1253-66. doi: 10.1016/S0041-0101(99)00227-5

94. Avila-Aguero ML, París MM, Hu S, Peterson PK, Gutiérrez JM, Lomonte B, et al. Systemic cytokine response in children bitten by snakes in Costa Rica. Pediatr Emerg Care. (2001) 17:425-9. doi: 10.1097/00006565-200112000-00006

95. De Souza CA, Kayano AM, Setubal SS, Pontes AS, Furtado JL, Kwasniewski $\mathrm{FH}$, et al. Local and systemic biochemical alterations induced by Bothrops atrox snake in mice. J Venom Res. (2012) 3:28-34.

96. Moreira V, Gutiérrez JM, Amaral RB, Zamunér SR, Teixeira CF. Effects of Bothrops asper snake venom on the expression of cyclooxygenases and production of prostaglandins by peritoneal leukocytes in vivo, and by isolated neutrophils and macrophages in vitro. Prostaglandins Leukotrienes Essent Fatty Acids. (2009) 80:707-14. doi: 10.1016/j.plefa.2008.11.009

97. Setubal SS, Pontes AS, Nery NM, Bastos JS, Castro OB, Pires WL, et al. Effect of Bothrops bilineata snake venom on neutrophil function. Toxicon. (2013) 76:143-9. doi: 10.1016/j.toxicon.2013.09.019

98. Martinon F, Burnes K, Tschopp J. The inflammasome: a molecular platform triggering activation of inflammatory caspases and processing of proIL-beta. Mol Cell. (2002) 10:417-26. doi: 10.1016/S1097-2765(02)00599-3

99. Palm NW, Medzhitov R. Role of inflammasome in defense against venoms. PNAS. (2013) 110:1809-14. doi: 10.1073/pnas.1221476110

100. Farsky SH, Gonçalves LR, Gutiérrez JM, Correa AP, Rucavado A, Gasque P, et al. Bothrops asper snake venom and its metalloproteinase BaP-1 activate the complement system. Role in leukocyte recruitment. Mediators Inflamm. (2000) 9:213-21. doi: 10.1080/09629350020025728

101. Delafontaine M, Villas-Boas IM, Pidde G, van den Berg CW, Mathieu L, Blomet J, et al. Venom from Bothrops lanceolatus, a snake species native to martinique, potently activates the complement system. J Immunol Res. (2018) 2018:3462136. doi: 10.1155/2018/3462136

102. Setubal SS, Pontes AS, Furtado JL, Kayano AM, Stabeli RG, Zuliani JP. Effect of Bothrops alternatus snake venom on macrophage phagocytosis and superoxide production: participation of protein kinase C. J Venom Anim Toxins Incl Trop. Dis. (2011) 17:430-41. doi: 10.1590/S1678-91992011000400010

103. Zamuner SR, Gutiérrez JM, Muscará MN, Teixeira SA, Teixeira CFP. Bothrops asper and Bothrops jararaca trigger microbicidal functions of peritoneal leukocytes in vivo. Toxicon. (2001) 39:1505-13. doi: 10.1016/S0041-0101(01)00123-4

104. Santosh SM, Sundaram MS, Sunitha K, Kemparaju K, Girish KS. Viper venom-induced oxidative stress and activation of inflammatory cytokines: a therapeutic approach for overlooked issues of snakebite management. Inflamm Res. (2013) 62:721-31. doi: 10.1007/s00011-013$0627-\mathrm{y}$

105. Santosh SM, Hemshekhar M, Thushara RM, Devaraja S, Kemparaju K, Girish KS. Vipera russelli venom induced oxidative stress and hematological alterations. Cell Biochem Funct. (2013) 31:41-50. doi: 10.1002/cbf.2858

106. Sunitha K, Hemshekhar M, Thushara RM, Santosh SM, Sundaram MS, Kemparaju $\mathrm{K}$, et al. Inflammation and oxidative stress in viper bite: an insight within and beyond. Toxicon. (2015) 98:80-97. doi: 10.1016/j.toxicon.2015.02.014

107. Chaves F, Teixeira C, Gutiérrez JM. Role of nitric oxide in the local and systemic pathophysiological effects induced by Bothrops asper snake venom in mice. Inflamm Res. (2006) 55:245-53. doi: 10.1007/s00011-006-0078-9

108. Teixeira C, Zamuner SR, Zuliani JP, Fernandes MC, Cruz-Hofling MA, Chaves F, et al. Neutrophils do not contribute to local tissue damage, but play a key role in skeletal muscle regeneration in mice injected with Bothrops asper snake venom. Muscle Nerve. (2003) 28:449-59. doi: 10.1002/mus.10453

109. Medzhitov R. TLR-mediated innate immune recognition Semin Immunol. (2007) 19:1-2. doi: 10.1016/j.smim.2007.02.001

110. Aderem A, Ulevitch RJ. Toll-like receptors in the induction of the innate immune response. Nature. (2000) 406:782-7. doi: 10.1038/35021228

111. Kawai T, Akira S. TLR signaling. Semin Immunol. (2007) 19:24-32. doi: 10.1016/j.smim.2006.12.004

112. Moreira V, Teixeira C, Borges Da Silva H, D’império Lima MR, Dos-Santos MC. The crucial role of the MyD88 adaptor protein in the inflammatory response induced by Bothrops atrox venom. Toxicon. (2013) 67:37-46. doi: 10.1016/j.toxicon.2013.02.010
113. Moreira V, Teixeira C, Borges da Silva H, D’Império Lima MR, DosSantos MC. The role of TLR2 in the acute inflammatory response induced by Bothrops atrox snake venom. Toxicon. (2016) 118:121-8. doi: 10.1016/j.toxicon.2016.04.042

114. Leiguez E, Giannotti KC, Moreira V, Matsubara MH, Gutiérrez JM, Lomonte B, et al. Critical role of TLR2 and MyD88 for functional response of macrophages to a group IIA-secreted phospholipase A2 from snake venom. PLoS ONE. (2014) 9:e93741. doi: 10.1371/journal.pone.0093741

115. Paiva-Oliveira EL, Ferreira da Silva R, Correa Leite PE, Cogo JC, QuiricoSantos T, Lagrota-Candido J. TLR4 signaling protects from excessive muscular damage induced by Bothrops jararacussu snake venom. Toxicon. (2012) 60:1396-403. doi: 10.1016/j.toxicon.2012.10.003

116. Smiley ST, King JA, Hancock WW. Fibrinogen stimulates macrophage chemokine secretion through toll-like receptor 4. J Immunol. (2001) 167:2887-94. doi: 10.4049/jimmunol.167.5.2887

117. Castro HC, Fernandes M, Zingali RB. Identification of bothrojaracin like proteins in snake venoms from Bothrops species and Lachesis muta. Toxicon. (1999) 37:1403-16. doi: 10.1016/S0041-0101(99)00087-2

118. Silva MB, Schattner M, Ramos CR, Junqueira-de-Azevedo IL, Guarnieri MC, Lazzari MA, et al. A prothrombin activator from Bothrops erythromelas (jararaca-da-seca) snake venom: characterization and molecular cloning. Biochem J. (2003) 369:129-39. doi: 10.1042/bj20020449

119. Modesto JC, Junqueira-de-Azevedo IL, Neves-Ferreira AG, Fritzen M, Oliva ML, Ho PL, et al. Insularinase A, a prothrombin activator from Bothrops insularis venom, is a metalloprotease derived from a gene encoding protease and disintegrin domains. Biol Chem. (2005) 386:589-600. doi: 10.1515/BC.2005.069

120. Berger M, Pinto AF, Guimarães JA. Purification and functional characterization of bothrojaractivase, a prothrombin-activating metalloproteinase isolated from Bothrops jararaca snake venom. Toxicon. (2008) 51:488-501. doi: 10.1016/j.toxicon.2007.09.005

121. Kitano ES, Garcia TC, Menezes MC, Tashima AK, Zelanis A, Serrano SM. Cotiarinase is a novel prothrombin activator fromthe venom of Bothrops cotiara. Biochimie. (2013) 95:1655-9. doi: 10.1016/j.biochi.2013.04.006

122. Sartim MA, Costa TR, Laure HJ, Espíndola MS, Frantz FG, Sorgi CA, et al. Moojenactivase, a novel pro-coagulant PIIId metalloprotease isolated from Bothrops moojeni snake venom, activates coagulation factors II and X and induces tissue factor up-regulation in leukocytes. Arch Toxicol. (2016) 90:1261-78. doi: 10.1007/s00204-015-1533-6

123. Fox JW, Serrano SM. Exploring snake venom proteomes: multifaceted analyses for complex toxin mixtures. Proteomics. (2008) 8:909-20. doi: 10.1002/pmic.200700777

124. Fox JW, Serrano SM. Structural considerations of the snake venom metalloproteinases, key members of the M12 reprolysin family of metalloproteinases. Toxicon. (2005) 45:969-85. doi: 10.1016/j.toxicon.2005.02.012

125. Zychar BC, Dale CS, Demarchi DS, Gonçalves LR. Contribution of metalloproteases, serine proteases and phospholipases A2 to the inflammatory reaction induced by Bothrops jararaca crude venom in mice. Toxicon. (2010) 55:227-34. doi: 10.1016/j.toxicon.2009.07.025

126. Fernandes CM, Zamuner SR, Zuliani JP, Rucavado A, Gutiérrez JM, Teixeira $\mathrm{CF}$. Inflammatory effects of $\mathrm{BaP} 1$ a metalloproteinase isolated from Bothrops asper snake venom: leukocyte recruitment and release of cytokines. Toxicon. (2006) 47:549-59. doi: 10.1016/j.toxicon.2006.01.009

127. Lopes DS, Baldo C, Oliveira CF, de Alcântara TM, Oliveira JD, Gourlart LR, et al. Characterization of inflammatory reaction induced by neuwiedase, a PI metalloproteinase isolated from Bothrops neuwiedi venom. Toxicon. (2009) 54:42-9. doi: 10.1016/j.toxicon.2009.03.007

128. Bernardes CP, Menaldo DL, Mamede CC, Zoccal KF, Cintra AC, Faccioli LH, et al. Evaluation of the local inflammatory events induced by BpirMP, a metalloproteinase from Bothrops pirajai venom. Mol Immunol. (2015) 68(2 Pt B):456-64. doi: 10.1016/j.molimm.2015.09.023

129. Costa EP, Clissa PB, Teixeira CFP, Moura-da-Silva AM. Importance of metalloproteinases and macrophages in viper snake envenomationinduced local inflammation. Inflammation. (2002) 26:13-7. doi: 10.1023/A:1014465611487

130. Silva CA, Zuliani JP, Assakura MT, Mentele R, Camargo AC, Teixeira CF, et al. Activation of alphaM beta2-mediated phagocytosis by HF3, a PIII class 
metalloproteinase isolated from the venom of Bothrops jararaca. Biochem Biophys Res Commun. (2004) 322:950-6. doi: 10.1016/j.bbrc.2004.08.012

131. Clissa PB, Laing GD, Theakston RDG, Mota I, Taylor MJ, MouradaSilva AM. The effect of jararhagin, a metalloproteinase from Bothrops jararaca venom, on pro-inflammatory cytokines released by murine peritoneal adherent cells. Toxicon. (2001) 39:1567-73. doi: 10.1016/S0041-0101(01)00131-3

132. Gallagher P, Bao Y, Serrano SM, Laing GD, Theakston RD, Gutierrez JM, et al. Role of the snake venom toxin jararhagin in proinflammatory pathogenesis: in vitro and in vivo gene expression analysis of the effects of the toxin. Arch Biochem Biophys. (2005) 441:1-15. doi: 10.1016/j.abb.2005.06.007

133. Pereira AL, Fritzen M, Faria F, Motta G, Chudzinski-Tavassi AM. Releasing or expression modulating mediator involved in hemostasis by Berythractivase and Jararhagin (SVMPs). Toxicon. (2006) 47:788-96. doi: 10.1016/j.toxicon.2006.02.014

134. Kini RM, Joseph JS, Rao VS. Prothrombin activators from snake venoms. In: Mènez A, editor. Perspectives in Molecular Toxinology. Chichester: John Wiley (2002). p. 341-55.

135. Kini RM. The intriguing world of prothrombin activators from snake venoms. Toxicon. (2005) 45:1133-45. doi: 10.1016/j.toxicon.2005.02.019

136. Joseph JS, Kini RM. Snake venom prothrombin activators similar to blood coagulation factor Xa. Curr DrugTargets Cardiovasc Haematol Dis. (2004) 4:397-416. doi: 10.2174/1568006043335781

137. Schattner M, Fritzen M, Ventura JS, de Albuquerque Modesto JC, Pozner RG, Moura-da-Silva AM, et al. The snake venom metalloproteases berythractivase and jararhagin activate endothelial cells. Biol Chem. (2005) 386:369-74. doi: 10.1515/BC.2005.044

138. Siigur J, Siigur E. Factor $\mathrm{X}$ activating proteases from snake venoms. Tox Rev. (2005) 25:235-55. doi: 10.1080/15569540600567305

139. Sajevic T, Leonardi A, KriŽaj I. Haemostatically active proteins in snake venoms. Toxicon. (2011) 57:627-45. doi: 10.1016/j.toxicon.2011.01.006

140. Egorina EM, Sovershaev MA, Hansen JB. The role of tissue factor in systemic inflammatory response syndrome. Blood Coagul Fibrinolysis. (2011) 22:4516. doi: 10.1097/MBC.0b013e328346ef3f

141. Breitenstein A, Camici GG, Tanner FC. Tissue factor: beyond coagulation in the cardiovascular system. Clin Sci. (2010) 118:159-72. doi: $10.1042 / C S 20080622$

142. Read MS, Shermer RW, Brinkhous KM. Venom coagglutinin: an activator of platelet aggregation dependent on von Willebrand factor. Proc Natl Acad Sci USA. (1978) 75:4514. doi: 10.1073/pnas.75.9.4514

143. Brinkhous KM, Read MS, Fricke WA, Wagner RH. Botrocetin (venom coagglutinin): reaction with a broad spectrum of multimeric forms of factor VI11 macromolecular complex. Proc Natl Acad Sci USA. (1983) 80:1463-6. doi: 10.1073/pnas.80.5.1463

144. Fujimura Y, Titani K, Usami Y, Suzuki M, Oyama R, Matsui T, et al. Isolation and chemical characterization of two structurally and functionally distinct forms of botrocetin, the platelet coagglutinin isolated from the venom of Bothrops jararaca. Biochemistry. (1991) 30:1957-64. doi: 10.1021/bi00221a032

145. De Luca M, Ward CM, Ohmori K, Andrews RK, Berndt MC. Jararhagin and jaracetin: novel snake venom inhibitors of the integrin collagen receptor, alpha 2 beta 1. Biochem Biophys Res Commun. (1995) 206:570-6. doi: 10.1006/bbrc.1995.1081

146. Kilpatrick DC. Animal lectins: a historical introduction and overview. Biochim Biophys Acta. (2002) 1572:187-97. doi: 10.1016/S0304-4165(02)00308-2

147. Ghazarian H, Idoni B, Oppenheimer SB. A glycobiology review: carbohydrates, lectins and implications in cancer therapeutics. Acta Histochem. (2011) 113:236-47. doi: 10.1016/j.acthis.2010.02.004

148. Morita T. C-type lectin-related proteins from snake venoms. Curr Drug Targets Cardiovasc Haematol Disord. (2004) 4:357-73. doi: $10.2174 / 1568006043335916$

149. Clemetson KJ. Snaclecs (snake C-type lectins) that inhibit or activate platelets by binding to receptors. Toxicon. (2010) 56:1236-46. doi: 10.1016/j.toxicon.2010.03.011

150. Eble JA. Structurally robust and functionally highly versatile-C-type lectin (-Related) proteins in snake venoms. Toxins. (2019) 11:E136. doi: $10.3390 /$ toxins 11030136
151. Pires WL, de Castro OB, Kayano AM, da Silva Setubal S, Pontes AS, Nery NM, et al. Effect of BjcuL, a lectin isolated from Bothrops jararacussu, on human peripheral blood mononuclear cells. Toxicol in vitro. (2017) 41:30-41. doi: 10.1016/j.tiv.2017.02.003

152. Panunto PC, da Silva MA, Linardi A, Buzin MP, Melo SE, Mello SM, et al. Biological activities of a lectin from Bothrops jararacussu snake venom. Toxicon. (2006) 47:21-31. doi: 10.1016/j.toxicon.2005.08.012

153. Dias-Netipanyj MF, Boldrini-Leite LM, Trindade ES, Moreno-Amaral AN, Elifio- Esposito S. Bjcul, a snake venom lectin, modulates monocyte-derived macrophages to a pro inflammatory profile in vitro. Toxicol in vitro. (2016) 33:118-24. doi: 10.1016/j.tiv.2016.02.023

154. Sartim MA, Riul TB, Del Cistia-Andrade C, Stowell SR, Arthur CM, Sorgi CA, et al. Galatrox is a C-type lectin in Bothrops atrox snake venom that selectively binds LacNAc-terminated glycans and can induce acute inflammation. Glycobiology. (2014) 24:1010-21. doi: 10.1093/glycob/ cwu061

155. Lu Q, Navdaev A, Clemetson JM, Clemetson KJ. Snake venom Ctype lectins interacting with platelet receptors. Structure-function relationships and effects on haemostasis. Toxicon. (2005) 45:1089-98. doi: 10.1016/j.toxicon.2005.02.022

156. Clemetson KJ, Lu Q, Clemetson JM. Snake C-type lectin-like proteins and platelet receptors. Pathophysiol Haemost Thromb. (2005) 34:150-5. doi: 10.1159/000092414

157. Wijeyewickrema LC, Berndt MC, Andrews RK. Snake venom probes of platelet adhesion receptors and their ligands. Toxicon. (2005) 45:1051-61. doi: $10.1016 /$ j.toxicon.2005.02.025

158. Wang WJ, Huang TF. A novel tetrameric venom protein, agglucetin from Agkistrodon acutus, acts as a glycoprotein Ib agonist. Thromb Haemost. (2001) 86:1077-86. doi: 10.1055/s-0037-1616536

159. Wang WJ, Ling QD, Liau MY, Huang TF. A tetrameric glycoprotein Ib-binding protein, agglucetin, from Formosan pit viper: structure and interaction with human platelets. Thromb Haemost. (2003) 90:465-75. doi: 10.1160/TH03-02-0072

160. Peng M, Lu W, Kirby EP. Alboaggregin-B: a new platelet agonist that binds to platelet membrane glycoprotein Ib. Biochemistry. (1991) 30:11529-36. doi: 10.1021/bi00113a007

161. Kowalska MA, Tan L, Holt JC, Peng M, Karczewski J, Calvete JJ, et al. Alboaggregins A and B. Structure and interaction with human platelets. Thromb Haemost. (1998) 79:609-13. doi: 10.1055/s-0037-1614954

162. Arpijuntarangkoon J, Rojnuckarin P, Muanpasitporn C, Kaeothip S, Sangvanich P, Intragumtornchai T. Molecular cloning and sequence analysis of alboaggregin B. Platelets. (2007) 18:266-72. doi: $10.1080 / 09537100601078232$

163. Huang KF, Ko TP, Hung CC, Chu J, Wang AH, Chiou SH. Crystal structure of a platelet-agglutinating factor isolated from the venom of Taiwan habu (Trimeresurus mucrosquamatus). Biochem J. (2004) 378:399407. doi: 10.1042/bj20031507

164. Lu Q, Navdaev A, Clemetson JM, Clemetson KJ. GPIb is involved in platelet aggregation induced by mucetin, a snake C-type lectin protein from Chinese habu (Trimeresurus mucrosquamatus) venom. Thromb Haemost. (2004) 91:1168-76. doi: 10.1160/TH03-12-0747

165. Chen ZM, Wu JB, Zhang Y, Yu GY, Lee WH, Lu QM, et al. Jerdonuxin, a novel snaclec (snake C-type lectin) with platelet aggregation activity from Trimeresurus jerdonii venom. Toxicon. (2011) 57:109-16. doi: $10.1016 /$ j.toxicon.2010.10.011

166. Morita, T. Structure-function relationships of C-type lectin-related proteins. Pathophysiol Haemost Thromb. (2005) 34:156-159. doi: 10.1159/0000 92415

167. Broos K, De Meyer SF, Feys HB, Vanhoorelbeke K, Deckmyn H. Blood platelet biochemistry. Thromb Res. (2012) 129:245-9. doi: 10.1016/j.thromres.2011.11.002

168. Marcinkiewicz C, Lobb RR, Marcinkiewicz MM, Daniel JL, Smith JB, Dangelmaier C, et al. Isolation and characterization of EMS16, a C-lectin type protein from Echis multisquamatus venom, a potent and selective inhibitor of the $\alpha 2 \beta 1$ integrin. Biochemistry. (2000) 39:9859-67. doi: 10.1021/bi000428a

169. Gale AJ. Continuing education course \#2: current understanding of hemostasis. Toxicol Pathol. (2011) 39:273-80. doi: $10.1177 / 0192623310389474$ 
170. Dutting S, Bender M, Nieswandt B. Platelet GPVI: a target for antithrombotic therapy? Trends Pharmacol Sci. (2012) 33:583-90. doi: 10.1016/j.tips.2012.07.004

171. Nieswandt B, Watson SP. Platelet-collagen interaction: is GPVI the central receptor? Blood. (2003) 102:449-61. doi: 10.1182/blood-200212-3882

172. Rayes J, Watson SP, Nieswandt B. Functional significance of the platelet immune receptors GPVI and CLEC-2. J Clin Investig. (2019) 129:12-23. doi: $10.1172 / J C I 122955$

173. Suzuki-Inoue K, Fuller GL, Garcia A, Eble JA, Pohlmann S, Inoue O, et al. A novel Syk-dependent mechanism of platelet activation by the C-type lectin receptor CLEC-2. Blood. (2005) 107:542-9. doi: 10.1182/blood-2005-051994

174. Bruserud O. The snake venom rhodocytin from Calloselasma rhodostomaa clinically important toxin and a useful experimental tool for studies of C-type lectin-like receptor 2 (CLEC-2). Toxins. (2013) 5:665-74. doi: 10.3390/toxins5040665

175. Colonna M, Samaridis J, Angman L. Molecular characterization of two novel C-type lectin-like receptors, one of which is selectively expressed in human dendritic cells. Eur J Immunol. (2000) 30:697-704. doi: 10.1002/15214141(200002)30:2<697::AID-IMMU697>3.0.CO;2-M
176. Zelensky AN, Gready JE. The C-type lectin-like domain superfamily. FEBS J. (2005) 272:6179-217. doi: 10.1111/j.1742-4658.2005.05031.x

177. Fuller GL, Williams JA, Tomlinson MG, Eble JA, Hanna SL, Pohlmann S, et al. The C-type lectin receptors CLEC-2 and Dectin-1, but not DC-SIGN, signal via a novel YXXL-dependent signaling cascade. J Biol Chem. (2007) 282:12397-409. doi: 10.1074/jbc.M609558200

178. Watson AA, O'Callaghan CA. Molecular analysis of the interaction of the snake venom rhodocytin with the platelet receptor CLEC-2. Toxins. (2011) 3:991-1003. doi: 10.3390/toxins3080991

Conflict of Interest Statement: The authors declare that the research was conducted in the absence of any commercial or financial relationships that could be construed as a potential conflict of interest.

Copyright (c) 2019 Teixeira, Fernandes, Leiguez and Chudzinski-Tavassi. This is an open-access article distributed under the terms of the Creative Commons Attribution License (CC BY). The use, distribution or reproduction in other forums is permitted, provided the original author(s) and the copyright owner(s) are credited and that the original publication in this journal is cited, in accordance with accepted academic practice. No use, distribution or reproduction is permitted which does not comply with these terms. 